\title{
Age and visual sensitivity in the rat
}

\author{
VIRGINIA L. GOETSCH and WALTER ISAAC \\ University of Georgia, Athens, Georgia
}

\begin{abstract}
The ability to detect low levels of light was studied in two age groups. It was found that the sensitivity of the younger rats (157 days old) was greater than the sensitivity of the older rats (420 days old). However, altering the olfactory environment produced an increase in sensitivity to light in both groups.
\end{abstract}

Prior research with humans has demonstrated changes in absolute brightness thresholds and rates of darkadaptation thatare related toaging(McFarland, Domey, Warren, \& Ward, 1960). It is commonly assumed that changes in light sensitivity that occur with aging are the consequence of changes in the peripheral visual apparatus. Considerable evidence has been gathered showing that changes in the eye do, in fact, accompany aging. McFarland et al. (1960) attributed the deficits that they observed to changes in retinal metabolism observed in the aged. Furthermore, yellowing of the lens and increased absorption of shorter wavelengths seen with aging (Said \& Weale, 1959) would handicap the aged subjects in the study by McFarland et al. (1960), since they used a violet stimulus. Such changes in the visual apparatus become important in the human between the ages of 55-65 years (Fozard, Wolf, Bell, McFarland, \& Podolsky, 1977). No comparable data with respect to changes in light sensitivity with aging are available for other animals, however.

The present study was designed to evaluate the visual sensitivity of young and old rats and to determine whether varying a central state of arousal would alter the visual sensitivity of the animals. Although varying arousal level by manipulating ambient illumination levels has been shown to alter auditory sensitivity in the monkey (Delay, Smith, \& Isaac, 1978), olfactory stimulation was used in the present study because of its marked effect upon the arousal level of the rat (Kenshalo \& Isaac, 1977).

\section{METHOD}

\section{Subjects}

Twelve male hooded rats, six aged 157 days and six aged 420 days at the start of the study, served as subjects. The animals were housed individually and had continuous access to food. They were given access to water daily for 20 min following each experimental session.

Requests for reprints should be directed to W. Isaac, Department of Psychology, University of Georgia, Athens, Georgia 30602.

\section{Apparatus}

The test apparatus was a light-tight plywood box with a black interior, measuring $47 \mathrm{~cm}$ long, $30 \mathrm{~cm}$ wide, and $34 \mathrm{~cm}$ high. The box sat on a table in a darkened room. One wall of the box was hinged at the bottom and had a magnetic latch at the top, giving access to the interior. The bottom of the box was covered with $1.25 \mathrm{~cm}$ of granulated clay (Cat Comfort Absorbant Litter). A grid floor, $1.25 \mathrm{~cm}$ above the clay, was formed by brass rods $.32 \mathrm{~cm}$ in diameter and separated by $1.25 \mathrm{~cm}$. At one end of the box, a removable plastic lever, $10 \times 2 \mathrm{~cm}$ (Davis Instrument Co.), was centered $3 \mathrm{~cm}$ above the grid floor. At the opposite end of the box, two round holes, $3.8 \mathrm{~cm}$ in diameter and $4.5 \mathrm{~cm}$ apart, were centered $4.0 \mathrm{~cm}$ above the grid floor. Each of these openings gave access to a transparent Plexiglas panel, hinged at the top, which, when pressed, closed a microswitch. An aluminum reinforcer pedestal, $2.0 \mathrm{~cm}$ in front of the wall and extending $1.0 \mathrm{~cm}$ above the grid, was centered between the two circular openings. A removable reinforcer of similar design, centered $2.5 \mathrm{~cm}$ in front of the lever, was used for part of the preliminary training procedure. A solenoid valve was set to deliver $.15 \mathrm{ml}$ of sugar water through the reinforcer pedestals.

Light stimuli were presented by a bank of light-emitting diodes located $7 \mathrm{~cm}$ behind the transparent Plexiglas panel behind the circular opening on the right side, with a frosted glass diffusion lens between the light source and the panel. The bank of 25 green $(540 \mathrm{~nm}$ ) light-emitting diodes (FLV 340), which produced a luminance of $1.0 \mathrm{fL}$ with steady application of current, were energized 77.8 times per second. The duration of the flashes was controlled by a solid state programming system. Thus, the intensity of the light stimulus remained constant $(1.0 \mathrm{fL})$, but the apparent brightness was varied by control of the flash durations. This method of varying the visual stimulus has been described in more detail elsewhere (Lorig, Golden, \& Isaac, 1980). In the present study, the on times of the flashes that were used were $4,6,8,10,14$, and $32 \mu \mathrm{sec}$. The levels of illumination produced were not visible to the human observer and therefore were not directly measurable.

Solid state programming equipment, located in an adjacent room, controlled the sequences of events and recorded the data obtained.

\section{Procedure}

During preliminary training, the subjects were trained to set up each trial by pressing the bar at one end of the box and to then press the right panel if it was illuminated or the left panel if the right panel remained dark. Following preliminary training, the equipment was programmed to allow for the occurrence of 60 trials, with 30 trials in which no light stimulus appeared behind the right panel and 30 trials in which 5 trials with each of the six flash durations were presented. The order of the stimulus conditions was randomized.

Prior to each daily session, each subject was placed in the experimental room to provide a similar opportunity for dark adap- 
tation at the beginning of each experimental session for all subjects. Obviously, with visual stimuli used in the procedure, it was impossible to maintain a constant level of dark adaptation during the experimental session.

After the performance of all subjects had stabilized, data were taken for an additional 12 days. Following those 12 days, the granulated clay, which had not been changed for either age group since the beginning of training, was replaced with $1.25 \mathrm{~cm}$ of clean clay, and data were gathered for an additional 6 days.

\section{RESULTS}

As may be seen in Figures 1 and 2, both groups reached a stable level of performance, as indicated by the lack of change in two successive 6-day blocks of trials. Analysis of these data yielded a significant difference between the two age groups $[F(1,10)=$ 7.76, $\mathrm{p}<.05$ ]. There was, of course, a significant difference in the number of detections across the levels of flash frequencies $[F(5,110)=117.55, p<$ $.01]$. The interaction between flash rates and age levels was also significant $[F(5,110)=5.36, p<$ $.01]$. The difference between blocks of trials did not

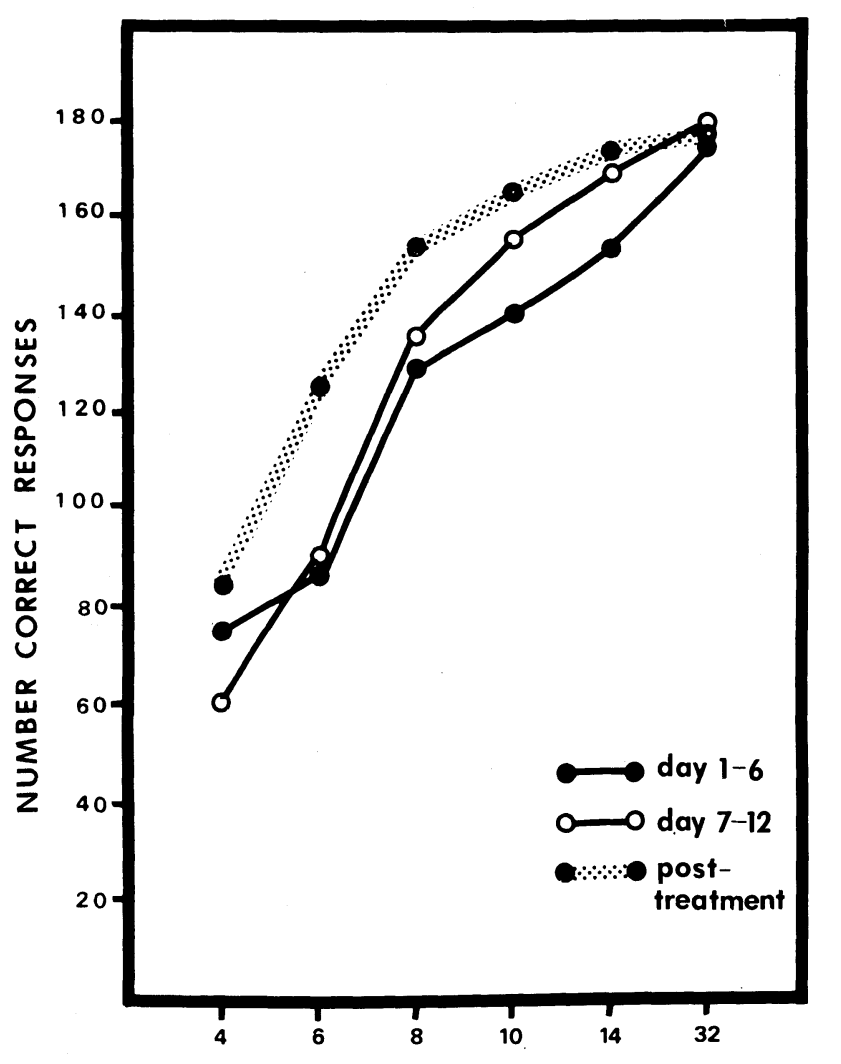

ON TIME

(microseconds)

Figure 1. Number of correct responses (detections) as related to the duration of the light flashes (apparent brightness) in younger animals.

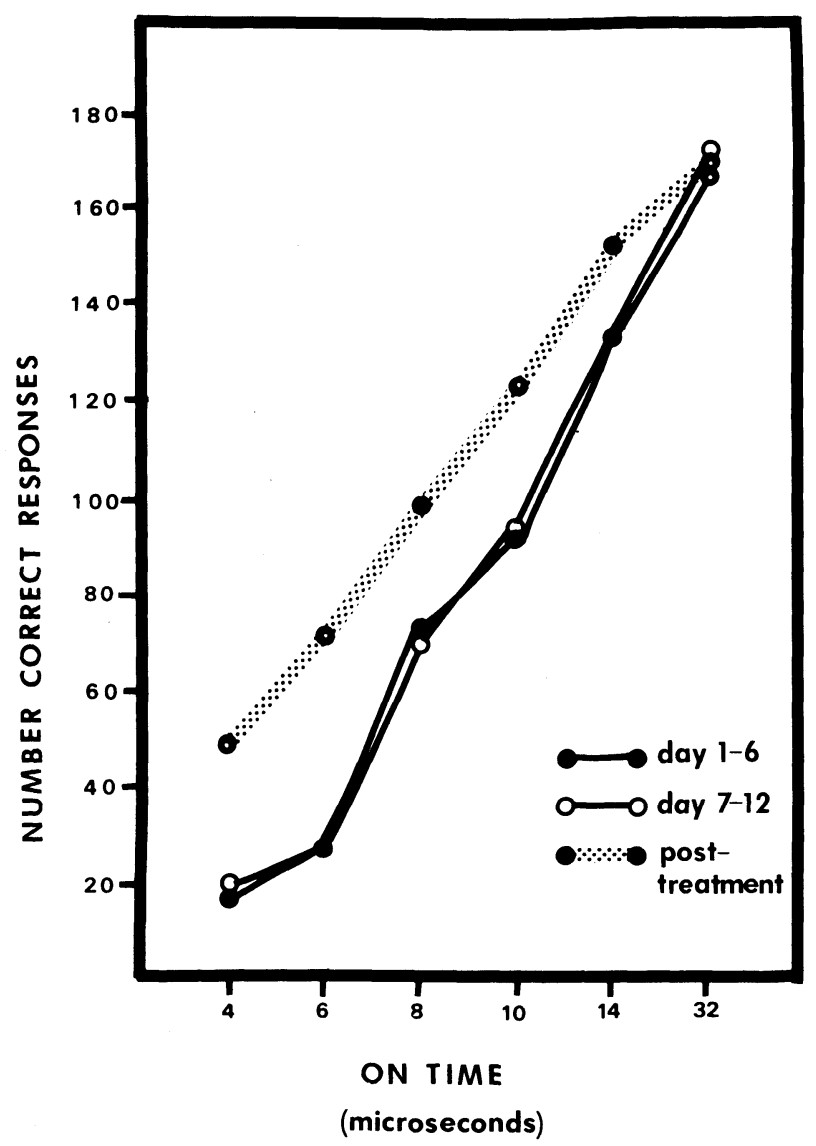

Figure 2. Number of correct responses (detections) as related to the duration of the light flashes (apparent brightness) in older animals.

approach significance, nor did any of its interactions, indicating that the performance of both groups had stabilized. The "false-alarm" rates of both age groups were nearly identical, with a total of 158 responses to the unlit panel, as if the light were on, for the younger animals and 153 such responses for the older animals. Because of the nonstandardized procedures required to train the subjects, no direct comparisons were made between the age groups with respect to the original learning of the task. However, in all cases, a greater length of time was required for the older subjects to reach the criterion set for stability of performance.

Comparing the performance of the two age groups during the last 6 days before the clay on the floor of the apparatus was changed with the performance during the 6 days immediately following the changing of the clay showed a significant improvement in performance following the change $[F(1,110)=29.16$, $\mathrm{p}<.01$ ]. A similar improvement was seen in both age groups; there was not a significant interaction between the effects of the two variables $[F(1,110)=$ $1.84, p>.05]$. The performance of the two age 
groups differed significantly $[\mathrm{F}(1,110)=7.28, \mathrm{p}<$ $.05]$, and the levels of flash rates produced a significant difference in rates of detections in both age groups $[F(5,110)=110.48, p<.01]$. The effects of age and flash rates were not independent, however, and a significant interaction between them was obtained $[F(5,110)=5.55, p<.01]$. The rate of detection of the six flash rates improved following the changing of the clay and produced an interaction that was not significant $[F(5,110)=2.23, p>.05]$.

\section{DISCUSSION}

In earlier studies, the effect of environmental conditions thought to vary arousal level upon sensory discriminations has been observed (Cone, 1967; Delay et al., 1978). The effectiveness of olfaction as an arousal stimulus for the rat (Kenshalo \& Isaac, 1977) led us to expect a change in visual sensitivity with the changing of the granulated clay in the present study. The increase in sensitivity in both age groups with the alteration in the environment emphasizes the fragile nature of any measures of absolute threshold and perhaps is critical of the concept of sensory threshold. In any case, these data emphasize the necessity of specifying conditions relevant to both the environment and the organism when dealing with problems of sensitivity to sensory stimuli.

While the differences between the two age groups were not unexpected, it should be emphasized that the age groups were not the extremes of the age range of these animals. The younger animals were older than the 90-day-old rat that is so commonly used in behavioral research; the older rats were well under the 3-year upper limit of their life span. Their ages, in fact, differed by less than 1 year. Other changes in the rat's response to visual information have been demonstrated in the middle portion of its life span (Isaac \& Baker, 1963). This study further suggests that age-related changes in the visual system do not necessarily occur only at the extremes of their age range.

Because of the different weights and sizes of the subjects in the two age groups, it is impossible to assume that identical water-deprivation schedules would produce identical drive states. However, the lack of any observed difference in the false-alarm scores for the two age groups would argue against a motivational difference between them and suggest that the criterion levels of both age groups were similar.

The change in sensitivity seen in both age groups with an alteration in the ambient sensory environment, with an assumed change in arousal levels, calls into question many of the deficiencies seen as the consequence of aging. The observed differences may indicate that the appropriate environment and conditions that produce maximum performance are different for the different age levels. Given different environmental stimulation, the older subjects might be found to perform at a higher level than originally assumed. The findings reported in the present study indicate that some of the inferior performance seen in older subjects on sensory tasks could be the consequence of a less than optimal arousal level rather than defects in the peripheral sense organs.

\section{REFERENCES}

Cone, A. L., JR. Effects of ambient sensory input and damphetamine upon roughness discrimination in the rhesus macaque. Unpublished doctoral dissertation, Emory University, 1967.

Delay, E. R., Smith, E. S., \& Isaac, W. Effects of illumination on auditory threshold. Physiology \& Behavior, 1978, 20, 201-202.

Fozard, J. L., Wolf, E., Bell, B., McFarland, R. A., \& Podolsky, S. Visual perception and communication. In J. E. Birren \& K. W. Shai (Eds.), Handbook of the psychology of aging. New York: Van Nostrand Reinhold, 1977.

IsAAC, W., \& BAKER, E. J. A changing effect of cortical ablation with age. Journal of Comparative and Physiological Psychol$o g y, 1963,56,167-168$.

Kenshalo, D. R., JR., \& IsaAc, W. Informational and arousal properties of olfaction. Physiology \& Behavior, 1977, 18, 1085-1087.

Lorig, T. S., Golden, A. J., \& IsAac, W. A programmable circuit for varying light intensity. Behavior Research Methods \& Instrumentation, 1980, 12, 639.

McFarland, R. A., Domey, R. G., Warken, A. B., \& Ward, D. C. Dark adaptation as a function of age: I. A statistical analysis. Journal of Gerontology, 1960, 15, 149-154.

SaId, F. S., \& Weale, R. A. The variation with age of the spectral transmissivity of the living human crystalline lens. Gerontologia, 1959, 3, 213-231.

(Manuscript received January 26, 1982;

revision accepted for publication April 27, 1982.) 